\title{
Gel Filtration Chromatography
}

National Cancer Institute

\section{Source}

National Cancer Institute. Gel Filtration Chromatography. NCI Thesaurus. Code C16433.

Gel permeation or sieve chromatography that is performed on porous gels that separate solutes on the basis of size. Smaller solutes are included within the particles of the gel matrix more frequently than larger solutes, thus affecting elution rates. 